\title{
Medulloblastoma with Melanotic Differentiation
}

National Cancer Institute

\section{Source}

National Cancer Institute. Medulloblastoma with Melanotic Differentiation. NCI

Thesaurus. Code C9497.

A rare malignant embryonal neoplasm characterized by the presence of small cells which resemble the cells of classic medulloblastoma and a minor population of melaninforming neuroepithelial cells. It usually has an unfavorable clinical course. 